\title{
Improving the information content in soil pH maps: a case study
}

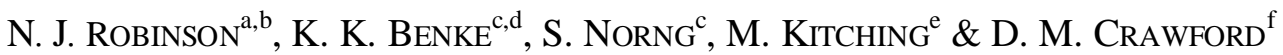 \\ ${ }^{\mathrm{a}}$ Faculty of Science and Technology, Federation University, University Drive, Mt Helen, Victoria, Australia, \\ 3350, ' Department of Economic Development, Jobs, Transport and Resources (DEDJTR) - Bendigo Centre, \\ Cnr Midland Hwy \& Taylor Street, Epsom, Victoria, Australia, 3554, 'Department of Economic Development, \\ Jobs, Transport and Resources (DEDJTR) - Parkville Centre, Lincoln Square North, Parkville, Victoria, \\ Australia 3052, 'School of Engineering, University of Melbourne, Grattan St, Parkville, Victoria, Australia, \\ 3010, 'Department of Economic Development, Jobs, Transport and Resources (DEDJTR) - Macleod Centre, \\ Ernest Jones Drive, Macleod, Victoria, Australia, 3085, and ${ }^{\mathrm{f}}$ Department of Economic Development, Jobs, \\ Transport and Resources (DEDJTR) - Ellinbank, Victoria, Australia, 3821.
}

Correspondence: N. J. Robinson. Email: Nathan.Robinson@ecodev.vic.gov.au Running title: Improving information content in soil pH maps

This is the author manuscript accepted for publication and has undergone full peer review but has not been through the copyediting, typesetting, pagination and proofreading process, which may lead to differences between this version and the Version of Record. Please cite this article as doi: 10.1111 /ejss. 12452

This article is protected by copyright. All rights reserved. 


\section{Summary}

Uncertainties associated with legacy data contribute to the spatial uncertainty of predictions for soil properties such as $\mathrm{pH}$. Examples of potential sources of error in maps of soil $\mathrm{pH}$ include temporal variation and changes in land use over time. Prediction of soil $\mathrm{pH}$ can be improved with a linear mixed model (LMM) to analyse factors that contribute to uncertainty. Probabilities from conditional simulations in combination with agronomic critical thresholds for acid-sensitive species can be used to identify areas that are likely, or very likely, to be below these critical thresholds for plant production. Because of rapid changes in farming systems and management practices, there is a need to be vigilant in monitoring changes in soil acidification. This is because soil acidification is an important factor in primary production and soil sustainability. In this research, legacy data from south-western Victoria (Australia) were used with model-based geostatistics to produce a map of soil $\mathrm{pH}$ that accommodates a variety of error sources such as the time of sampling, seasonal variation, differences in analytical method, effects of changes in land use and variable soil sample depth in legacy data. Spatial covariates that are representative of soil-forming factors were used to improve predictions. To transform spatial prediction and estimates of error in soil $\mathrm{pH}$ into more informative and usable maps with more information content, simulations from the conditional distribution were used to compute the probability of soil $\mathrm{pH}$ being less than critical agronomic production thresholds at each of the prediction locations. These probabilities were mapped to reveal areas of potential risk.

Keywords: modelling, probability, simulation, epistemic uncertainty, GRUMP, south-western Victoria 


\section{Highlights}

- Can maps of soil $\mathrm{pH}$ be improved by accounting for temporal variation and change in land use?

- $\quad$ First example of taking account of temporal variability in sampling for $\mathrm{pH}$ in spatial models.

- Key factors for uncertainty in spatial prediction include time of sampling and sample depth.

- Accuracy improved by accounting for additional sources of error combined with conditional simulations.

\section{Introduction}

A primary threat to the quantity and quality of food production worldwide is soil acidification (FAO \& ITPS, 2015). Globally, acid soil occurs on $30 \%$ of the ice-free land mass (von Uexküll \& Mutert, 1995). There is the potential for human-induced causes including the drainage of land, land-use change and intensification (e.g. from native systems to productive agriculture), acid rain and the application of acidifying nitrogen fertilizers to accelerate soil acidification rates. In Australia, 50-million hectares of agricultural land are estimated to have surface layers with $\mathrm{pH}$ values less than or equal to 5.5, which causes annual production losses of \$AUD 1585 million (NLWRA, 2002).

Realistic statements about soil properties, such as $\mathrm{pH}$ and its decrease over time (soil acidification), are a current priority for many countries including Australia (Department of Agriculture, 2014). Reliable spatial estimates are necessary to establish baselines for soil pH 
and improve targeted interventions to manage soil acidity. Some countries have invested in purpose-built soil-monitoring networks (Arrouays et al., 2012), whereas many others are using available soil information (often referred to as legacy data) to formulate the current state of soil degradation and changes in soil condition (Marchant et al., 2015). Legacy data used for such purposes can be convenient, but they also present many potential issues that must be resolved. Inaccuracy in site location, bias in sample design, sparseness and clustering of sample sites (Marchant et al., 2013), imprecise and inaccurate field and laboratory measurements (Raupach, 1954; Raupach \& Tucker, 1959; White, 1969; Laslett \& McBratney, 1990) and out-dated analytical methods that are incompatible with current methods, all contribute errors to modelling and mapping.

So, how do we make better maps to represent soil properties of interest? Ultimately, a better map should include new knowledge that enables a user to make better decisions. The lack of a clear and concise representation of the soil property of interest, and an over-reliance on subjective knowledge, can lead to incorrect assumptions on the effects of land use and management on soil $\mathrm{pH}$. To support land managers, we need to provide them with tailored spatial soil information that is compatible with and timely for their decision making, easily interpreted and applied, and with uncertainty defined.

To make a map more ćomprehensibleôfor users and thus reduce risk in their decisions, new approaches are required that can integrate data with associated errors, reduce the effects of these errors and make intended users aware of errors. Here, systematic approaches can prove useful in the development and creation of a soil map. The error budget procedure of Nelson et al. (2011), for example, combines the relative contribution from stochastic error sources in 
digital soil mapping (DSM: McBratney et al., 2003) and has been adapted for soil salinity mapping (Huang et al., 2015). Potential sources of error considered in the error budget include environmental covariates (e.g. error in digital elevation models), soil property measurements (e.g. accuracy and precision), errors in models and the location of sites; all known as aleatory uncertainty (Walker et al., 2005; Benke et al., 2007).

In DSM, a conventional focus of the uncertainty assessment has been on statistical variability using error propagation or other stochastic methods. Epistemic uncertainty because of imperfect knowledge or assumptions can be considerable. In general, this uncertainty can be reduced through the attainment of new knowledge to reduce the effects of misdiagnosis, misinterpretation or incorrect implementation. In mapping soil $\mathrm{pH}$, examples of epistemic uncertainties include: measurement error for different methods of $\mathrm{pH}$ analysis, temporal cycles in $\mathrm{pH}$, model specification and assumptions, incorrect environment and conditions in the framing of models, assessments and legacy data used.

Robinson et al. (2015) describe a framework, the global representation of uncertainty in the modelling process (GRUMP), to integrate epistemic and aleatory uncertainties. The GRUMP framework supports explicit definition, organization and quantification of these error sources in a modelling process. The sources of aleatory and epistemic uncertainties can be quantified or enumerated through experiments, expert opinion or explicit knowledge. This enables comparison between assessment techniques for uncertainty and the ability to modify these depending on user perceptions of uncertainty (McBratney, 1992; Robinson et al., 2015). 
In this research, we combine legacy data with model-based geostatistics to predict soil $\mathrm{pH}$ and associated error for two catchments in south-western Victoria (Australia). We attempt to accommodate error sources which contribute to epistemic uncertainty that have rarely been included in previous DSM applications, such as the time of sampling and seasonal variation, differences in analytical methods, effects of land-use change and variable soil sample depth in legacy data. In this example, these error sources are viewed as contributing to epistemic uncertainty. Spatial covariates that represent soil forming factors are also used to improve our predictions. To transform spatial prediction and error estimates of soil $\mathrm{pH}$ into informative and usable maps, a spatial simulation technique is used to approximate the probability of soil $\mathrm{pH}$ being less than critical agronomic thresholds. An explanation of how this process has led to improved information (better maps) is also presented.

\section{Materials and methods}

\section{Study area}

The study area of $14000 \mathrm{~km}^{2}$ in south-western Victoria comprises the catchments of the Hopkins River and Lake Corangamite (Figure 1). It is part of the Western Plains and Western Uplands geomorphological divisions of Victoria (Rees et al., 2010) with low-lying undulating plains of volcanic and sedimentary origin and Palaeozoic bedrock formations that form upland residuals at various elevations. The volcanic plains comprise deposits from eruptions over the last 5 million years, including overlapping basalt flows with palaeosols and pyroclastic deposits from scoria cones and tuff. The soil of the Western Plains is of variable 
age and pedogenic development. Most soil types belong to three Soil Orders of the Australian Soil Classification (Isbell, 2002); they are Sodosols, Chromosols and Vertosols. Dermosols, or profiles that can be strongly acidic (Kurosols), occur in the higher rainfall landscapes of the study area (Robinson et al., 2003).

\section{Land use}

Livestock production systems in south-western Victoria have dominated landscapes since European settlement in the 1830s. This includes sheep production (wool and meat), beef cattle production, dairy and mixed farming (Gibbons \& Downes, 1964). Animal husbandry has been supported by improved pastures and there have been considerable increases in the number of livestock. In 2000, the majority of the study area was either under improved pastures or native grassland. This was determined from a supervized classification of Landsat scenes, aerial photograph interpretation and field validation (Sinclair et al., 2012). When this was compared with the 2014 land-use statistics from the Victorian Land Use Information System (VLUIS; Morse-McNabb et al., 2015), more than 300000 ha of land (22\% of the study area) have been converted from pasture to forestry or grain production (Figure 2). The accuracy of prediction of land-use classes for $2014\left(R^{2}=0.66\right)$ was less than that for the landuse map of $2000\left(R^{2}=0.88\right)$. This is attributed to the use of MODIS imagery in the 2014 assessment and that field calibration and validation were considerably less than for the landuse dataset for 2000. The expansion of cropping, based on the comparison of the 2000 and 2014 land-use datasets, was largely in regions where cropping enterprises already existed in 2000. 


\section{Soil data}

In the study area, 828 sites were sampled between 1957 and 2015 (Figure 1; Table 1) from 13 soil and land surveys. Sites include topsoil samples from profile descriptions, monitoring sites and soil fertility samples. Of the 828 sites, 174 (21\%) were from paddocks where landuse has changed since 2000 (Figure 2c) and 126 of these 174 sites were sampled prior to 2000.

Soil pH measurements from methods 4A1 (pHw) and a modified 4B5 (pHwmir) (Rayment \& Lyons, 2011) used in this study are summarized in Table 2. Measurements since 2010 for method 4A1 (equivalent to ISO 10390:2005) were obtained with a Radiometer Analytical SAS titration system (Radiometer, Lyon, France) comprising a PHM92 pH meter and CDM240 conductivity meter. Between 1992 and 2010 a comparable automated system was used with control samples and a test sample (personal communication, B. Shelley, Melbourne, Australia, February 2015) to account for instrument drift (Laslett \& McBratney, 1990). Prior to 1992, $\mathrm{pH}$ was determined with equipment from the same manufacturer with samples left to equilibrate in monitored room conditions before analysis. Instrumental error is reported as $\pm 0.1 \mathrm{pH}$ units.

Measurements for $\mathrm{pHwmir}$ were included where there were no available $\mathrm{pHw}$ measurements to form a combined dataset, hereon referred to as pHw. Mid-infrared (MIR) diffuse reflectance spectroscopy has been used since 2004 for rapid estimation of soil properties (e.g. pHw) with archived and research samples submitted to the DEDJTR chemistry laboratories. 
The samples for mid-infrared (MIR) diffuse reflectance spectroscopy were ground finely to ensure a standardized particle-size distribution $(>95 \%<100 \mathrm{\varepsilon m})$ and scanned with a PerkinElmer Spectrum One Fourier Transform MIR spectrometer (PerkinElmer, Glen Waverly, Victoria, Australia) at $8 \mathrm{~cm}^{-1}$ resolution, from 450 to $7800 \mathrm{~cm}^{-1}$ for one minute. Spectra were averaged and background readings recorded for every 10 samples. Predictions and error estimates were determined by partial least squares regression (PLSR) from a calibration model including more than 11000 samples. Diagnostic model parameters including the $R^{2}$, the root mean squared error of calibration (RMSEC), root mean squared error of cross validation (RMSECV) and root mean squared error of prediction (RMSEP) were used to assess the pHwmir model. The RMSECV is derived using the same equation as the RMSEC, except when are samples excluded from the formulation of the calibration model. The RMSEP is calculated with the same equation, but with a set of samples that are independent of the calibration set. Model statistics reported include an $R^{2}$ calibration of $0.877, R^{2}$ cross validation of $0.880, R^{2}$ prediction of 0.848 , RMSEC of 0.563 , RMSECV of 0.563 and RMSEP of 0.630 .

RMSEC $=\overline{\bar{\sum}}$, where $y_{i}$ and are the predicted and observed $\mathrm{pH}$ values, and $n$ is the number of calibration data.

Digital soil mapping (DSM) McBratney et al. (2003) provide a framework for predicting soil properties based on Jennyôs soil forming factors (Jenny, 1941) across regions of interest. Environmental variables were 
selected for each soil forming factor (soil, climate, organisms, relief, parent material, time and spatial position) (Table 3), then spatially reprojected to the EPSG:3111 coordinate system (GDA94 / Vicgrid94) and resampled to a 1000-m resolution by the nearest neighbour method for computational efficiency in model-based geostatistics.

Model-based geostatistics. Model estimation and spatial prediction were done with a linear mixed model (LMM) to predict $\mathrm{pH}_{\mathrm{W}}$ from available environmental spatial covariates and to account for important factors in the observed $\mathrm{pH}_{\mathrm{W}}$, such as time of sampling, sample depth and land-use change. The LMM separates the fixed effects $(\boldsymbol{\beta})$ as the linear model between $\mathrm{pH}_{\mathrm{W}}$ and the important explanatory variables from the random effects $(\mathbf{u})$, which are modelled to identify spatial dependence as the error. The equation also has an error term $(\boldsymbol{\varepsilon})$ :

where is a vector of responses, is a vector of unknown fixed effects and is a design matrix relating the response variable to those fixed effects, is a vector of unknown random effects and the design matrix relates the observations ( ) to the random effects. The error term is a vector of the independent random errors from measurement imprecision or inaccuracy and variation from processes over short distances that are not represented in the sample set (the nugget variance). See Lark et al. (2006) for further details on LMM.

The LMMs for alternative models were fitted with spatial covariates as fixed effects and the spatial coordinates (covariance structure) as the random effects with the likfit function in the geoR package (Ribeiro \& Diggle, 2001), which uses the maximum likelihood (ML) 
estimation method. Nine different covariance models were fitted, including the spherical model and eight different models using the Matérn function (Matérn, 1986) with different smoothness parameters $(\kappa)$ of $0.05,0.1,0.2,0.3,0.5,1,1.5$ and 2 . The optimum model (out of the nine) was selected based on the likelihood ratio test and used as the single alternative model. The null model was fitted in a similar way, but with the mean only (no fixed effects) and with spatial coordinates as the random effects, as with the alternative models. To determine which spatial covariates (fixed effects) to use in the parsimonious model, we fitted each of the fixed terms sequentially, followed by likelihood ratio tests between models to determine whether or not a fixed effect is included at the 5\% level of significance. To illustrate the benefits of including spatial covariates and fixed effect factors (e.g. land-use change, sample depth and sampling time, i.e. season), we fitted two models. Model 1 included no factors or environmental covariates and is a spatial dependence model with a constant mean (the null model). Model 2 included the significant fixed effects identified in the previous step (parsimonious model) to demonstrate the reduction in prediction error from their inclusion in a model-based design. The models were compared with the Akaike information criterion (AIC; Akaike, 1973):

$$
\mathrm{AIC}=-2+2
$$

where $L$ is the ML $\log$-likelihood and $q$ is the number of parameters in the model. The model with the smaller AIC is preferred; it represents a compromise between model simplicity and quality of fit. To compare models directly and the associated fixed effects, the ML method of estimation was used rather than residual maximum likelihood (REML). The same grid as that 
used for the environmental variables was used for spatial prediction with both sets of models (see below) and the predictions were compared spatially.

\section{Fixed effects used in modelling}

Some of the major fixed effects used in the LMMs included sample depth, which was a twolevel factor where topsoil samples either corresponded with the depth interval $0 \ddot{1} 10 \mathrm{~cm}$, or not (e.g. were greater than this $10-\mathrm{cm}$ interval, Figure 3). Sites were assigned to the four seasons in Victoria (Winter, June to August; Spring, September to November; Summer, December to February; Autumn, March to May) according to their sample date (Figure 4). Land-use was determined from the 2014 land-use spatial dataset with two classes assigned, pasture or crop. Land-use change was defined spatially by comparing the land-use maps from

2000 and 2014 (Figure 2). The frequency of land-use enterprise for the 2009 to 2014 period from the VLUIS was used to assess and validate the mapping of land-use change. Estimates of the variance for the predicted data were also used to compare the two models. Nelson et al. (2011) showed that uncertainty from positional error was relatively small in the error budget with model-based geostatistics, therefore, we did not include this source of error into the design of the investigation. 
Probability of pHw being below critical agronomic thresholds

A simulation of 5000 realizations for the conditional spatial distribution of $\mathrm{pH}$ was generated and stored at each of the predicted locations. These simulated $\mathrm{pH}$ data were then used to approximate the probability that $\mathrm{pHw}$ at a known location is above or below a given $\mathrm{pH}$ value, e.g. 5.3 for perennial pastures and 6.0 for brassicas (Brassica rapa L.) (see Slattery \& Coventry, 1993; Slattery et al., 1995). The approach used by Lark et al. (2014) adopted the likelihood scale of the Intergovernmental Panel on Climate Change (IPCC) to describe quantified uncertainty using verbal scales (Mastrandrea et al., 2010). These probabilities were then converted to verbal scales and mapped to support users where there was a potential need for intervention on land-use and management. The scheme we have applied (Table 4) has not been translated into unambiguous management outcomes as recommended by Lark et al. (2014), rather the purpose was to illustrate the use of probability methods to convey to users the relative uncertainty associated with the accuracy of map estimates.

\section{Results}

\section{Establishment of fixed and random effects}

The soil pHw LMM included factors from legacy data and environmental covariates that were identified as important from the likelihood ratio test (Table 5). Factors from the legacy data included sample depth and season (Spring, Summer, Autumn and Winter). The factors pH method and land-use change were excluded because they improved the model little. Environmental covariates included were elevation, land use (pasture or crop) and the NDVI 
Timesat derivative maximum amplitude for 2009 (NDVI 2009). The plot of standardized residuals from the LMM (Figure 5) supports the assumption of normality in the model. The seasonality of differences in $\mathrm{pHw}$ is evident in the measurements of soil $\mathrm{pH}$ (Figure 4) for the 0ï 10-cm sample depth where values are highest in winter and decrease during the following seasons (spring and summer) before increasing slightly in autumn.

\section{Spatial prediction of $\mathrm{pHw}$}

The prediction of $\mathrm{pHw}$ with the constant mean model (Model 1) was compared with the results from the LMM with fixed effects (Model 2) to establish whether fixed effect factors were significant in their contribution to a reduction in the error. Figure 6 shows the two models for $0 \ddot{1} 10 \mathrm{~cm}$ and their associated variance estimates (the results for summer are given for Model 2). Predictions for depths greater than $0 \mathrm{I} 10 \mathrm{~cm}$ were derived, but are not included here. The $\mathrm{pHw}$ predictions in Figure 6 emphasize visually the relative differences in $\mathrm{pH}$, in particular between $\mathrm{pH} 5$ and 6; this is the $\mathrm{pH}$ range at which many agronomic decisions are made with respect to crop type and remediation of soil acidity. The variance estimates in Figure 6 are presented to illustrate the relative differences between the models. Where the land use was other than pasture or grain production, $\mathrm{pH}$ was not predicted spatially. The addition of fixed effect factors reduced the AIC from 1595 to 1499 , which indicates a reduction in the error of prediction of $\mathrm{pH}$ and seasonal departures from a constant mean model (Table 6). Associated model parameters and very significant variables are listed in Tables S1 and S2 in the Supporting Information. 
Overall, the mean predictions on a seasonal basis for Model 2 varied between 10.02 and 0.28 from the constant mean model (Model 1). The estimates of variance for all seasons of Model 2 were smaller than those for Model 1, but only marginally. This is to be the expected because the spatial covariates included in Model 2 result in more accurate predictions because of the additional information contained in these variables. The inclusion of fixed effect factors, such as season and sample depth, is important and represents a departure from conventional model-based geostatistical approaches used in DSM.

The seasonal differences in the map predictions for $\mathrm{pHw}$ and associated variance estimates defined in the LMM are evident for 0ï $10 \mathrm{~cm}$ (Figure 7). Autumn and spring both display similar patterns with slight fluctuations in $\mathrm{pHw}$ for northern and western parts of the study area. There is a sharp contrast with summer where there are considerably larger areas of lower $\mathrm{pHw}$ in south-western areas with values approaching 5.2 or lower. Autumn has similar patterns to summer, but, it is evident that $\mathrm{pHw}$ values have increased slightly from a low in the summer.

\section{Probability of limiting soil pH conditions}

The probability maps (Figure 8a,b) with the verbal scale recommended by Mastrandrea et al. (2010) represent the uncertainty in spatial predictions of soil pHw. Our maps use a redï yellowï blue colour scheme because this has been the preferred scheme by users of volcanic hazard maps (Thompson et al. 2015) to reflect a progression from hazard (red hues) to absence of hazard (blue hues). The probabilities have been translated into verbal scales 
(Table 4) to illustrate that a large proportion of the Hopkins and Corangamite basins is likely to have limiting $\mathrm{pHw}$ conditions ( $\mathrm{pHw}$ Oे.0) during the crop growing season where brassicas and other acid sensitive species (e.g. barely, phalaris) are included in management rotations (see Figure 8a). Areas surrounding, and to the east of, Lake Corangamite, are designated with the verbal probability classes: unlikely to very unlikely to have a topsoil pHw Ö.0.

The map with probabilities of pHw Ò5.3 (Figure 8b) defines areas where agricultural plants more acid-tolerant than brassicas, barley (Hordeum vulgare L.) or phalaris (Phalaris aquatica L.) may be limited by soil acidity. For example, in the Western Uplands near Ararat (Figure 1) agronomic conditions are likely to be limiting for the remaining permanent pastures because of acidity, and therefore potential toxicity from aluminium and manganese. Where these pastures are leys in rotations, amelioration with lime in the arable part of the rotation is likely to be required when plants of the Fabaceae family (grain legumes) are sown. Likewise, there are areas to the east of Penshurst that are likely to have limiting pHw conditions, but here amelioration would occur either when they are re-sown or when lime is broadcast, a less effective option. These northern areas have less rainfall (mean annual rainfall at Ararat is 584 $\mathrm{mm}$ ) and support pastures sown with subclover (Trifolium subterraneum), whereas permanent pastures in the south receive more rain, e.g. mean annual rainfall at Colac is 729 $\mathrm{mm}$, and can be sown with white clover (Trifolium repens). Subclover is not as tolerant of low $\mathrm{pH}$ as white clover, therefore, it is likely that soil $\mathrm{pH}$ will have less effect on these more tolerant species in the area south of Lake Corangamite and Colac that abuts the Otway Range (the Southern Uplands). These landscapes are known to have acid soil including Kurosols (Robinson et al., 2003). 


\section{Discussion}

This study shows that map users can have more accurate information by accounting for potential error sources with the GRUMP framework in which predictions are based on taking into consideration factors such as seasonal variation and land-use effects. Legacy soil data issues are rarely, if ever, addressed in soil maps, but the research reported here shows that sources of error which introduce uncertainty can be quantified and accounted for by systematic analytic approaches.

Cyclical seasonal variation in soil $\mathrm{pH}$ is recognized (Slattery \& Ronnfeldt, 1992; Conyers et al., 1997); however, to our knowledge, this is the first example where time of year (translated into season) of sampling and temporal variation are accounted for in the creation of a soil $\mathrm{pH}$ map. The cyclical pattern of $\mathrm{pH}$ values is consistent with results from previous trials in northeastern Victoria that result from a low in summer and peak in late autumn to mid-winter and early-spring when the soil is at its wettest, and then decreasing in late spring to early summer when the soil is drying (Slattery \& Ronnfeldt, 1992). For gross changes in soil acidity to be quantified, variation in soil $\mathrm{pH}$ will need to exceed temporal flux and other sources of error (e.g. spatial variation) to enable detection. There could be other confounding factors in the assessment of seasonal variation in $\mathrm{pH}$ with legacy data because of differences in climate across years, or because sampling for $\mathrm{pH}$ might have been done at different stages of crop or pasture rotations. 
Land-use change was marginally significant only, but it is a potential factor in the change of soil $\mathrm{pH}$. Changes in pasture composition and a reliance on legume based pastures (e.g. subterranean clover) have been recognized as causing more land to become acidic in Australia (Coventry, 1985). In south-western Victoria, there are changes in farming systems from those with a focus on pastures to those of cropping or forestry. Soil acidification has been observed in pastures for this region (Crawford et al., 1994) and conversion to cropping might accelerate further the net rate of acid addition. Slattery et al. (1998) collated data from previous research and found that rates of acidification for cerealï legume rotations (1.0 to 7.5 $\mathrm{kmol}\left(\mathrm{H}^{+}\right) \mathrm{ha}^{-1}$ year $\left.^{-1}\right)$ were considerably larger than for pastures $\left(0.16\right.$ and $3.6 \mathrm{kmol}\left(\mathrm{H}^{+}\right) \mathrm{ha}^{-1}$ year $^{-1}$ ). Remediation of soil acidity in south-western Victoria typically occurs through liming in late summer to early autumn before the following winter crop, which is generally more sensitive to acid conditions (e.g. canola, Brassica napus L.).

Changes in $\mathrm{pH}$ with depth are well known, and this study showed that different sample depths contributed to differences in soil $\mathrm{pH}$. Variation in soil $\mathrm{pH}$ with depth is recognized and is strongly associated with soil type. Variation within 0 to $10 \mathrm{~cm}$ can also be considerable (McLaughlin et al., 1990). There were significant $(P<0.05)$ differences between the sample depths for $\mathrm{pH}$.

Our LMM analysis showed that there was no significant discrepancy between the different pH methods (4A1 and 4B5). This is consistent with the findings of Nelson et al. (2011) that showed analytical error was relatively minor in the total assessment of uncertainty. 
The inclusion of environmental covariates as fixed effects representing soil forming factors improved predictions of soil pH. This was identified by Nelson et al. (2011) as a way of reducing model error. The study area in south-western Victoria is larger than areas featured in other studies of the error budget and uncertainty (e.g. Nelson et al., 2011; Huang et al., 2015); it includes legacy data with real artefacts and errors that compound to affect spatial prediction of soil $\mathrm{pH}$. By harmonizing some of these epistemic sources of error, with guidance from the GRUMP framework, model-based geostatistics has enabled more reliable soil $\mathrm{pH}$ maps to be created.

The application of probability-based schemes with verbal scales to convey uncertainties is a recent development in the communication of soil information to users (see Lark et al., 2014; Marchant et al., 2015). This technique has been implemented in our study to convey to land users where areas with limiting soil $\mathrm{pH}$ conditions are likely and represent a potential limitation to plant production. The use of conditional simulations for the two $\mathrm{pH}$ thresholds (5.3 and 6.0) also provides an opportunity to guide future sampling and analysis to improve the certainty of predictions and cost-effectiveness of remediation (e.g. is it better to focus on areas where soil $\mathrm{pH}$ is ábout as likely as notôbelow a critical agronomic threshold). By accounting for factors that contribute to uncertainty in model-based approaches and use of verbal scales to convey degrees of uncertainty, we can construct maps of greater utility than conventional soil $\mathrm{pH}$ maps.

The maps presented here are more informative, are more useful and provide more statistical confidence than previous maps. The reasons for this are that: (i) conventional maps produced from previous surveys did not include a measure of uncertainty or error (i.e. there was no 
indication of risk in decision-making or data quality), (ii) national attempts to predict soil $\mathrm{pH}$ have been based largely on soil fertility test datasets with sites georeferenced using town localities or local authority area (e.g. NLWRA, 2002; Walter et al., 1997), and samples taken purposively to aid management of a paddock rather than for mapping soil $\mathrm{pH}$ at a regional scale, (iii) national maps of soil $\mathrm{pH}$ have been based on datasets collated from historical soil surveys, but data from 42 sites only were in the study area (e.g. NLWRA, 2002), (iv) no analyses to our knowledge have considered potential sources of error in the cyclical behaviour of soil $\mathrm{pH}$ and (v) the implementation of conditional simulations, together with critical agronomic thresholds and use of verbal scales of uncertainty, provides land users with map information of direct applicability.

There are further opportunities to improve the approach reported here. First, model specification could be refined to integrate further epistemic sources of error including expert opinion and additional data (e.g. field $\mathrm{pH}$ determinations) with probabilistic methods, such as Monte Carlo simulation. This can be guided by the so-called error budget approach. Second, a model ensemble approach that incorporates pre-existing maps and new maps from other techniques (e.g. data mining) could be investigated. This would provide an opportunity to explore further the effects of location error for model-based geostatistical approaches and data mining techniques. Third, there remain large deficiencies in the dispersion of soil sites across temporal and spatial domains for this region to quantify the spatial and temporal trends in the $\mathrm{pH}$ measurements (Marchant et al., 2015). This issue requires further attention if we are to refine and improve soil $\mathrm{pH}$ maps, because legacy data, which are often used in DSM, 
might represent historical soil conditions that have been modified by new and different farming methods with different rates of acidification.

Development of future soil maps should take account of these factors through repeated analysis of suitable sites in a purpose-built soil-monitoring network with a spatio-temporal statistical design (see de Gruijter et al., 2006) that meets the desired confidence levels negotiated between the soil scientist, geostatistician and decision maker.

\section{Conclusion}

There is a continuing need for vigilance in monitoring changes in soil acidity, a condition that can have adverse effects on primary production and the environment. Prediction of soil properties and their spatial distribution, however, are subject to uncertainties related to accuracy of the data when legacy data are used. In this paper, a legacy dataset from southwestern Victoria was used with model-based geostatistics to produce maps of soil $\mathrm{pH}$ and uncertainty that addressed a variety of sources of error. The linear mixed model (LMM) identified significant factors that contributed to uncertainty in our results and enabled more informative maps with improved information content to be produced for the prediction of soil $\mathrm{pH}$. Probabilities from conditional simulations when applied in combination with critical thresholds for the production of acid sensitive species can define areas that are likely to be below these thresholds. We have demonstrated that user-friendliness of the uncertainty map produced was improved by including a verbal scale of uncertainty together with a numerical scale. 


\section{Supporting Information}

The following supporting information is available in the online version of this article:

Table S1. Parameter estimates and model statistics for the constant mean (Model 1) and LMM (Model 2).

Table S2. Very significant terms (variables) added sequentially for the LMM.

\section{Acknowledgements}

The authors thank Kohleth Chia for supporting the implementation of spatio-temporal models in this paper. Comments and suggestions provided by Richard MacEwan, Mark Imhof, Jonathan Hopley, David Rees and Dr Peter Dahlhaus are greatly appreciated. Dialogue with Professor Murray Lark and Dr Ben Marchant as part of the Soil Change Matters Workshop (2014) contributed to the development of this research. We would also like to acknowledge the contributions of anonymous reviewers for comments on this manuscript. Support from the Land Knowledge Foundations and Rapid Analytics for Soil Productivity projects, both funded by DEDJTR, enabled this research to be undertaken. Nathan Robinson is jointly funded by the Federation University Australia and the DEDJTR. 


\section{References}

Akaike, H. 1973. Information theory and the maximum likelihood principle, In: Second International Symposium on Information Theory (eds B.N. Petrov \& F Csáki), pp. 267ï 281. Akadémiai Kiadó, Budapest.

Arrouays, D., Marchant, B.P., Saby, N.P.A., Meersmans, J., Orton, T.G., Martin, M.P., et al. 2012. Generic issues on broad-scale soil monitoring schemes: A review. Pedosphere, 22, $456 і ̈ 469$.

Benke, K.K., Hamilton, A.J. \& Lowell, K.E. 2007. Uncertainty analysis and risk assessment in the management of environmental resources. Australasian Journal of Environmental Management, 14, $243 і ̈ 249$.

Conyers, M.K., Uren, N.C., Helyar, K.R., Poile, G.J. \& Cullis, B.R. 1997. Temporal variation in soil acidity. Australian Journal of Soil Research, 35, 1115ï 1130.

Coventry, D.R. 1985. Changes in Agricultural Systems on Acid Aoils in Southern Australia. Crop and Pasture Production' Science and Practice. Australian Society of Agronomy, Hobart.

Crawford, D.M., Baker, T.G. \& Maheswaran, J. 1994. Soil pH changes under Victorian pastures. Australian Journal of Soil Research, 32, $105 і 111$.

Department of Agriculture 2014. The National Soil Research, Development and Extension Strategy, Securing Australia's Soil, for profitable industries and healthy landscapes. Department of Agriculture, Canberra. 
Diggle, P.J. \& Ribeiro Jnr, P.J. 2007. Model-based Geostatistics. Springer, New York, NY.

Eklundh, L. \& Jonsson, P. 2015. TIMESAT 3.2 with Parallel Processing. Software Manual, Department of Earth and Ecosystem Sciences, Lund University, Lund, Sweden, [WWW document]. URL http://www.nateko.lu.se/TIMESAT. [accessed on 12 January 2016].

FAO, ITPS 2015. Status of the World's Soil Resources (SWSR)-Technical Summary. Food and Agriculture Organisation of the United Nations and Intergovernmental Technical Panel on Soils, Rome, Italy.

Gallant, J.C. \& Austin, J.M. 2015. Derivation of terrain covariates for digital soil mapping in Australia. Soil Research, 53, $895 і ̈ 906$.

Gallant, J.C. \& Dowling, T.I. 2003. A multiresolution index of valley bottom flatness for mapping depositional areas. Water Resources Research, 39, 1347.

Gibbons, F.R. \& Downes, R.G. 1964. A Study of the Land in South-Western Victoria. Soil Conservation Authority, Kew, Victoria.

Huang, J., Zare, E., Malik, R.S. \& Triantafilis, J. 2015. An error budget for soil salinity mapping using different ancillary data. Soil Research, 53, 561 ï 575.

Isbell, R.F. 2002. The Australian Soil Classification, Revised Edition. Australian Soil and Land Survey Handbooks Series 4. CSIRO Publishing, Melbourne.

Jenny, H. 1941. Factors of Soil Formation. McGraw-Hill, New York. 
Lark, R.M., Ander, E.L., Cave, M.R., Knights, K.V., Glennon, M.M. \& Scanlon, R.P. 2014. Mapping trace element deficiency by cokriging from regional geochemical soil data: A case study on cobalt for grazing sheep in Ireland. Geoderma, 226-227, 64 ï 78.

Lark, R.M., Cullis, B.R., \& Welham, S.J. 2006. On spatial prediction of soil properties in the presence of a spatial trend: the empirical best linear unbiased predictor (E-BLUP) with REML. European Journal of Soil Science, 57, 787ï 799.

Laslett, G.M. \& McBratney, A.B. 1990. Estimation and implications of instrumental drift, random measurement error and nugget variance of soil attributesð a case study for soil pH. Journal of Soil Science, 41, 451 ï 471.

Marchant, B.P., Crawford, D.M. \& Robinson, N.J. 2015. What can legacy datasets tell us about soil quality trends? Soil acidity in Victoria. IOP Conference Series: Earth and Environmental Science, 25, 012015.

Marchant, B.P. \& Lark, R.M. 2007. The Matérn variogram model: Implications for uncertainty propagation and sampling in geostatistical surveys. Geoderma, 140, 337ї 345.

Marchant, B.P., Viscarra Rossel, R.A. \& Webster, R. 2013. Fluctuations in method-ofmoments variograms caused by clustered sampling and their elimination by declustering and residual maximum likelihood estimation. European Journal of Soil Science, 64, $401 і ̈ 409$. 
Mastrandrea, M.D., Field, C.B., Stocker, T.F., Edenhofer, O., Ebi, K.L., Frame, D.J., et al. 2010. Guidance Note for Lead Authors of the IPCC Fifth Assessment Report on Consistent Treatment of Uncertainties. Intergovernmental Panel on Climate Change, [WWW document]. URL http://www.ipcc.ch [accessed on the 5 February 2016].

Matérn, B. 1986. Spatial Variation. Lecture Notes in Statistics, No 36. Springer, New York, NY.

McBratney, A.B. 1992. On variation, uncertainty and informatics in environmental soil management. Australian Journal of Soil Research, 30, 913 ï 935.

McBratney, A.B., Mendonça Santos, M.L. \& Minasny, B. 2003. On digital soil mapping. Geoderma, 117, $3 і ̈ 52$.

McLaughlin, M., Baker, T., James, T. \& Rundle, J. 1990. Distribution and forms of phosphorus and aluminium in acidic topsoils under pastures in south-eastern Australia. Australian Journal of Soil Research, 28, 371 ï 385.

Morse-McNabb, E., Sheffield, K., Clark, R., Lewis, H., Robson, S., Cherry, D., et al. 2015. VLUIS, a land use data product for Victoria, Australia, covering 2006 to 2013. Scientific Data, 2, 150070.

Nelson, M.A., Bishop, T.F.A., Triantafilis, J. \& Odeh, I.O.A. 2011. An error budget for different sources of error in digital soil mapping. European Journal of Soil Science, 62, $417 і ̈ 430$.

This article is protected by copyright. All rights reserved. 
NLWRA, 2002. Australians and Natural Resource Management. National Land and Water Resources Audit, Commonwealth of Australia, Canberra.

Raupach, M. 1954. The errors involved in pH determination in soils. Australian Journal of Agricultural Research, 5, 716 ï 729.

Raupach, M. \& Tucker, B.M. 1959. The field determination of soil reaction. Journal of the Australian Institute of Agricultural Science, 25, 1291133.

Rayment, G.E. \& Lyons, D.J. 2011. Soil Chemical Methods: Australasia, 3. CSIRO Publishing, Melbourne.

Rees, D., Robinson, N., Imhof, M., Joyce, E.B. \& MacEwan, R. 2010. Spatial frameworks to support digital soil mapping. In: Proceedings 19th World Congress of Soil Science, Brisbane, Australia: Soil Solutions for a Changing World (eds R. Gilkes \& N. Prakongkep), pp. 50ï 53. International Union of Soil Sciences, Crawley.

Ribeiro Jnr, P.J. \& Diggle, P.J. 2001. geoR: A package for geostatistical analysis. $R$ News, 1, $15 \mathrm{I} 18$.

Robinson, N., Rees, D., Reynard, K., MacEwan, R., Dahlhaus, P., Imhof, M., et al. 2003. A Land Resource Assessment of the Corangamite Region. Department of Primary Industries, Epsom, Victoria, Australia.

Robinson, N.J., Benke, K.K. \& Norng, S. 2015. Identification and interpretation of sources of uncertainty in soils change in a global systems-based modelling process. Soil Research, 53, $592 і ̈ 604$. 
Sinclair, S.J., White, M.D., Medley, J., Smith, E. \& Newell, G.R. 2012. Mapping the past: Constructing a digital land-use history map for Victoria, Australia. Proceedings of the Royal Society of Victoria, 124, 193 ï 206.

Slattery, W. \& Coventry, D. 1993. Response of wheat, triticale, barley, and canola to lime on four soil types in north-eastern Victoria. Australian Journal of Experimental Agriculture, 33, 609ї 618.

Slattery, W., Morrison, G. \& Coventry, D. 1995. Liming effects on soil exchangeable and soil solution cations of 4 soil types in north-eastern Victoria. Australian Journal of Soil Research, 33, 277ï 295.

Slattery, W.J., Edwards, D.G., Bell, L.C., Coventry, D.R. \& Helyar, K.R. 1998. Soil acidification and the carbon cycle in a cropping soil of north-eastern Victoria. Australian Journal of Soil Research, 36, $273 і ̈ 290$.

Slattery, W.J. \& Ronnfeldt, G.R. 1992. Seasonal variation of pH, aluminium, and manganese in acid soils from north-eastern Victoria. Australian Journal of Experimental Agriculture, 32, $1105 і ̈ 1112$.

Thompson, M.A., Lindsay, J.M. \& Gaillard, J.C. 2015. The influence of probabilistic volcanic hazard map properties on hazard communication. Journal of Applied Volcanology, 4, 1 ï 24.

Von Uexküll, H.R. \& Mutert, E. 1995. Global extent, development and economic impact of acid soils. Plant and Soil, 171, 1 ï 15. 
Walker, W.E., Harremoes, P., Rotmans, J., van der Sluijs, J.P., van Asselt, M.B.A., Janssen, P., et al., 2005. Defining uncertainty: A conceptual basis for uncertainty management in model-based decision support. Integrated Assessment, 4, 5 ï 17.

Walter, C., Schvartz, C., Claudot, B., Bouedo, T. \& Aurousseau, P. 1997. Synthèse nationale des analyses de terre réalisées entre 1990 et 1994 II. Descriptions statistique et cartographique de la variabilité des horizons de surface des sols cultivés. Etude et Gestion des Sols, 4, 205 ï 220.

White, R.E. 1969. On the measurement of soil pH. The Journal of the Australasian Institute of Agricultural Science, 35, $3 \ddot{1} 14$.

Wilford, J. 2012. A weathering intensity index for the Australian continent using airborne gamma-ray spectrometry and digital terrain analysis. Geoderma, 183-184, $1241 \ddot{1} 142$. 


\section{Captions}

Figure 1. Soil sampling sites and their space-time distribution in south-western Victoria.

Figure 2. (a) Land use in 2000 and (b) 2014, and (c) changes between 2000 and 2014.

Figure 3. The distribution of $\mathrm{pH}$ with sample depth for the two depths $(0 \ddot{\mathrm{I}} 10$ or $0 \mathrm{i} 10+\mathrm{cm})$.

Figure 4. Seasonal differences in $\mathrm{pHw}$.

Figure 5. Histogram of standardized residuals for the LMM (Model 2).

Figure 6. Spatial prediction of $\mathrm{pHw}$ (left) and variance estimates (right) for pasture and grain land uses with: (a) Model 1 and (b) Model 2 in summer.

Figure 7. Spatial prediction of $\mathrm{pHw}$ (left) and variance estimates (right) for pasture and grain land uses in: (a) Winter, (b) Spring, (c) Summer and (d) Autumn.

Figure 8. Mapped probabilities that $\mathrm{pHw}$ was less than, or equal to (a) 6.0 and (b) 5.3 for autumn. 
Table 1. Soil sites $(N)$ for the collection periods.

\begin{tabular}{lr}
\hline Collection period & $N$ \\
\hline 1950 ï 1960 & 5 \\
1961 10̈ 1970 & 15 \\
1971 1ї 1980 & 22 \\
1981 1̈ 1990 & 444 \\
1991 20̈ 2000 & 144 \\
2001 20̈ 2010 & 74 \\
2011 2015 & 124 \\
\hline
\end{tabular}

This article is protected by copyright. All rights reserved. 
Table 2. Summary statistics for $\mathrm{pH}$ measurements.

\begin{tabular}{llllllllll}
\hline Method & $N$ & Minimum & $1^{\text {st }}$ Quantile & Median & Mean & $3^{\text {rd }}$ Quantile & Maximum & $\begin{array}{l}\text { Standard } \\
\text { deviation }\end{array}$ & Skew \\
\hline pHw & 625 & 4.3 & 5.1 & 5.4 & 5.52 & 5.8 & 10.2 & 0.68 & 0.143 \\
pHwmir & 203 & 4.0 & 5.07 & 5.53 & 5.71 & 6.12 & 8.71 & 0.86 & 0.135 \\
\hline
\end{tabular}

This article is protected by copyright. All rights reserved. 
Table 3. Environmental (spatial) covariates used in digital soil mapping.

\begin{tabular}{|c|c|c|c|}
\hline Factor & Variable name & Description & Agency or Source \\
\hline \multirow[t]{7}{*}{ S (soil) } & Victoria land units & Victorian soil type mapping from & Department of Economic \\
\hline & & harmonized legacy surveys with & Development, Jobs, Transport \\
\hline & & 3,300 land units & and Resources (DEDJTR) \\
\hline & Land use & Tertiary dominant land-cover class & Department of Economic \\
\hline & & for 2014. & Development, Jobs, Transport \\
\hline & & & and Resources (DEDJTR); \\
\hline & & & Morse-McNabb et al. (2015) \\
\hline \multirow[t]{6}{*}{$\mathrm{C}$ (climate) } & Mean rainfall/ mm, & Average annual rainfall (mm) & Australian Bureau of \\
\hline & $1960 і ̈ 1989$ & between 1960 and 1989. & Meteorology \\
\hline & Prescott index & Prescott index is an estimate of the & CSRIO; Gallant \& Austin \\
\hline & & water balance including leaching & $(2015)$ \\
\hline & & potential from evaporation and & \\
\hline & & precipitation data & \\
\hline \multirow[t]{3}{*}{ O (organisms) } & NDVI 2009 & MODIS NDVI 2009 Timesat & DEDJTR; Eklundh \& Jönsson \\
\hline & & derivative (maximum amplitude) & $(2015)$ \\
\hline & & using a Savitzkyï Golay filter. & \\
\hline \multirow[t]{11}{*}{$\mathrm{R}$ (relief) } & Elevation $/ \mathrm{m}$ & Vicmap elevation DTM $20 \mathrm{~m}$ is at a & Department of Environment, \\
\hline & & spatial resolution of $20 \mathrm{~m}$ and is & Land, Water and Planning \\
\hline & & derived from data of various & (DELWP) \\
\hline & & resolutions, accuracies and ages & \\
\hline & & with increased detail in local areas. & \\
\hline & Slope/ \% & Slope gradient (\%) ï derived from & Department of Environment, \\
\hline & & the DTM $20 \mathrm{~m}$ & Land, Water and Planning \\
\hline & & & (DELWP) \\
\hline & MrVBF & Derived from Elevation Ï Multi- & Gallant \& Dowling (2003) \\
\hline & & resolution valley bottom flatness & \\
\hline & & index & \\
\hline \multirow{7}{*}{$\begin{array}{l}\mathrm{P} \text { (parent } \\
\text { material) }\end{array}$} & Weathering intensity & Weathering intensity index - degree & Geoscience Australia; Wilford \\
\hline & index & that primary minerals are altered to & $(2012)$ \\
\hline & & secondary clay minerals and oxides. & \\
\hline & GRSÏ K & Gamma radiometric potassium & DEDJTR \\
\hline & & concentration from natural gamma & \\
\hline & & rays to a depth of approximately 40 & \\
\hline & & $\mathrm{cm}$. & \\
\hline
\end{tabular}


Table 4. Verbal probability descriptors used for pHw scenarios (Ò.3 and Ò.0)

\begin{tabular}{lc}
\hline Verbal descriptor & Probability \% \\
\hline Exceptionally unlikely & $0 і ̈ 1$ \\
Very unlikely & 1 Ï 10 \\
Unlikely & $10 і ̈ 33$ \\
About as likely as unlikely & $33 і ̈ 66$ \\
Likely & $66 і ̈ 90$ \\
Very likely & $90 і ̈ 99$ \\
Virtually certain & $99 і ̈ 100$ \\
\hline
\end{tabular}

This article is protected by copyright. All rights reserved. 
Table 5. Summary statistics for environmental covariates and factors (e.g. sample depth) used in the likelihood ratio test for the LMM (Model 2).

\begin{tabular}{lr}
\hline Fixed effect & $P$ value \\
\hline NDVI 2009 & 0.007 \\
Land use & $<0.010$ \\
Sample depth/cm & 0.015 \\
Season & 0.029 \\
Elevation/m & 0.068 \\
Victoria land units & 0.096 \\
pH source & 0.120 \\
Weathering intensity index & 0.133 \\
Slope/\% & 0.225 \\
Land-use change & 0.328 \\
Prescott index & 0.433 \\
MrVBF & 0.437 \\
Mean rainfall/mm & 0.943 \\
\hline
\end{tabular}

This article is protected by copyright. All rights reserved. 
Table 6. Mean soil $\mathrm{pH}$ prediction and variance estimates for Model 2 and Model 1 (in brackets) for $0 \ddot{1} 10 \mathrm{~cm}$.

\begin{tabular}{lllll}
\hline & Winter & Spring & Summer & Autumn \\
\hline Prediction & $5.48(5.50)$ & $5.63(5.50)$ & $5.34(5.50)$ & $5.57(5.50)$ \\
Variance & $0.36(0.39)$ & $0.36(0.39)$ & $0.36(0.39)$ & $0.36(0.39)$ \\
\hline
\end{tabular}

This article is protected by copyright. All rights reserved. 


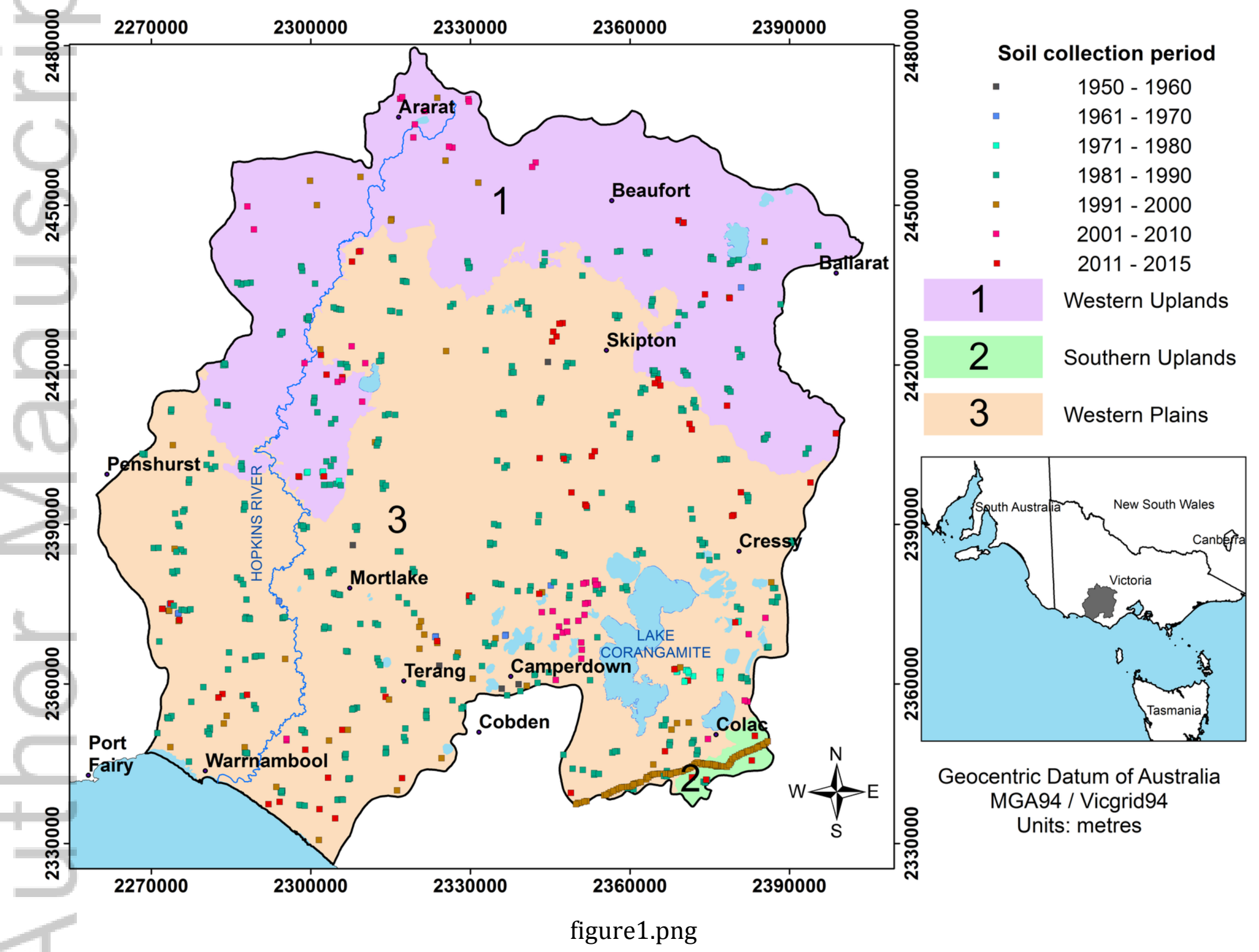

This article is protected by copyright. All rights reserved. 


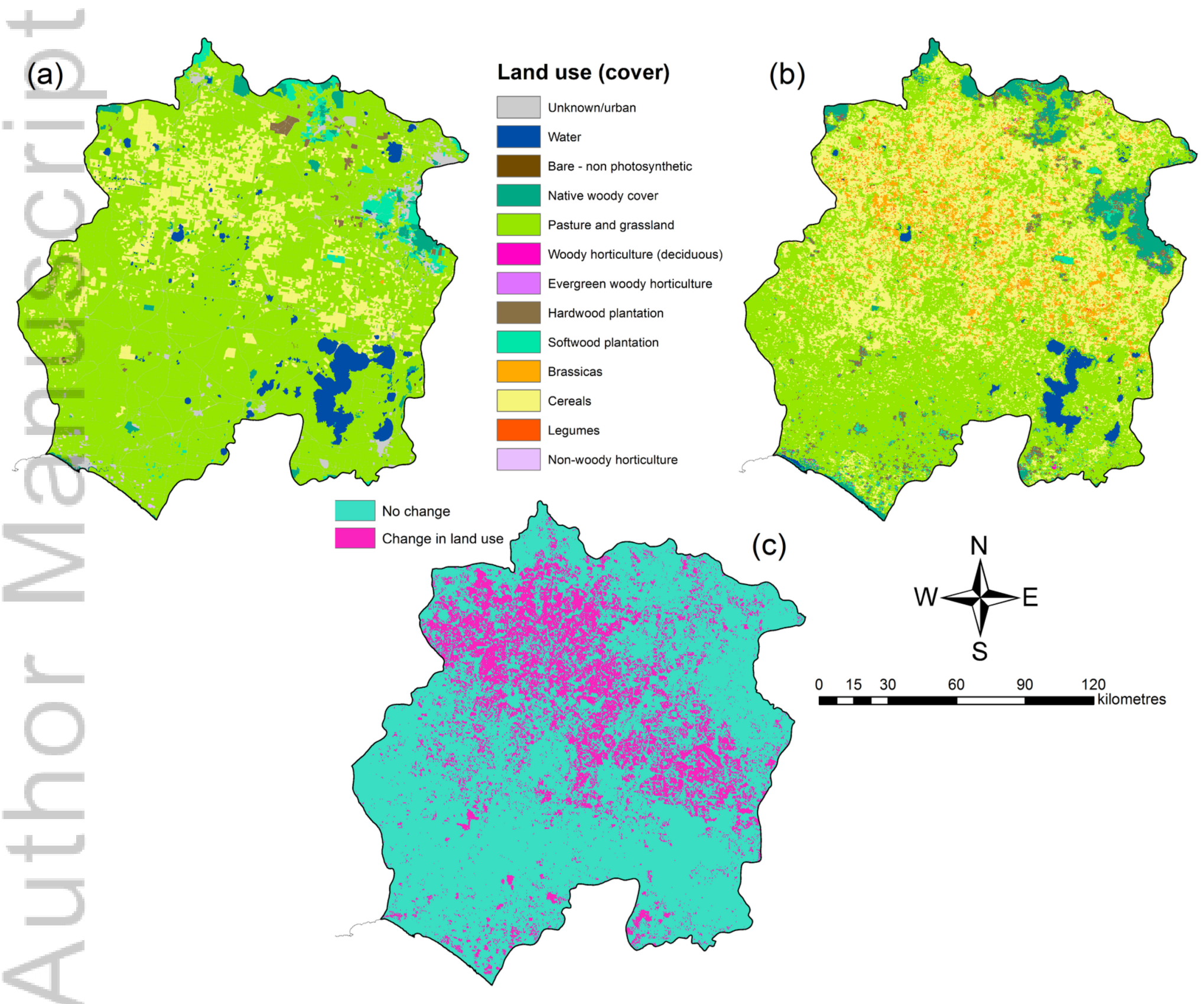

figure2.png 


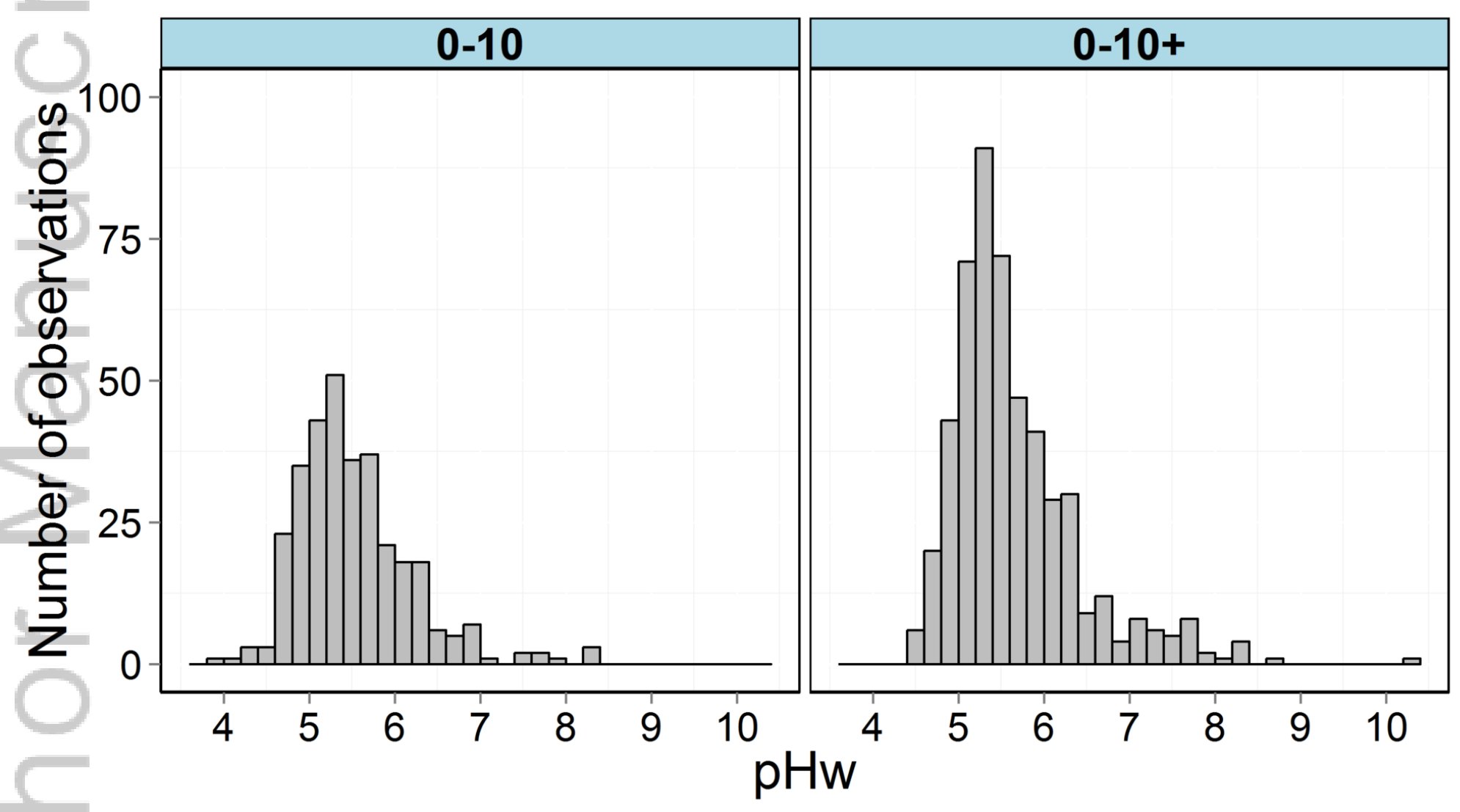

figure3 (1).png 


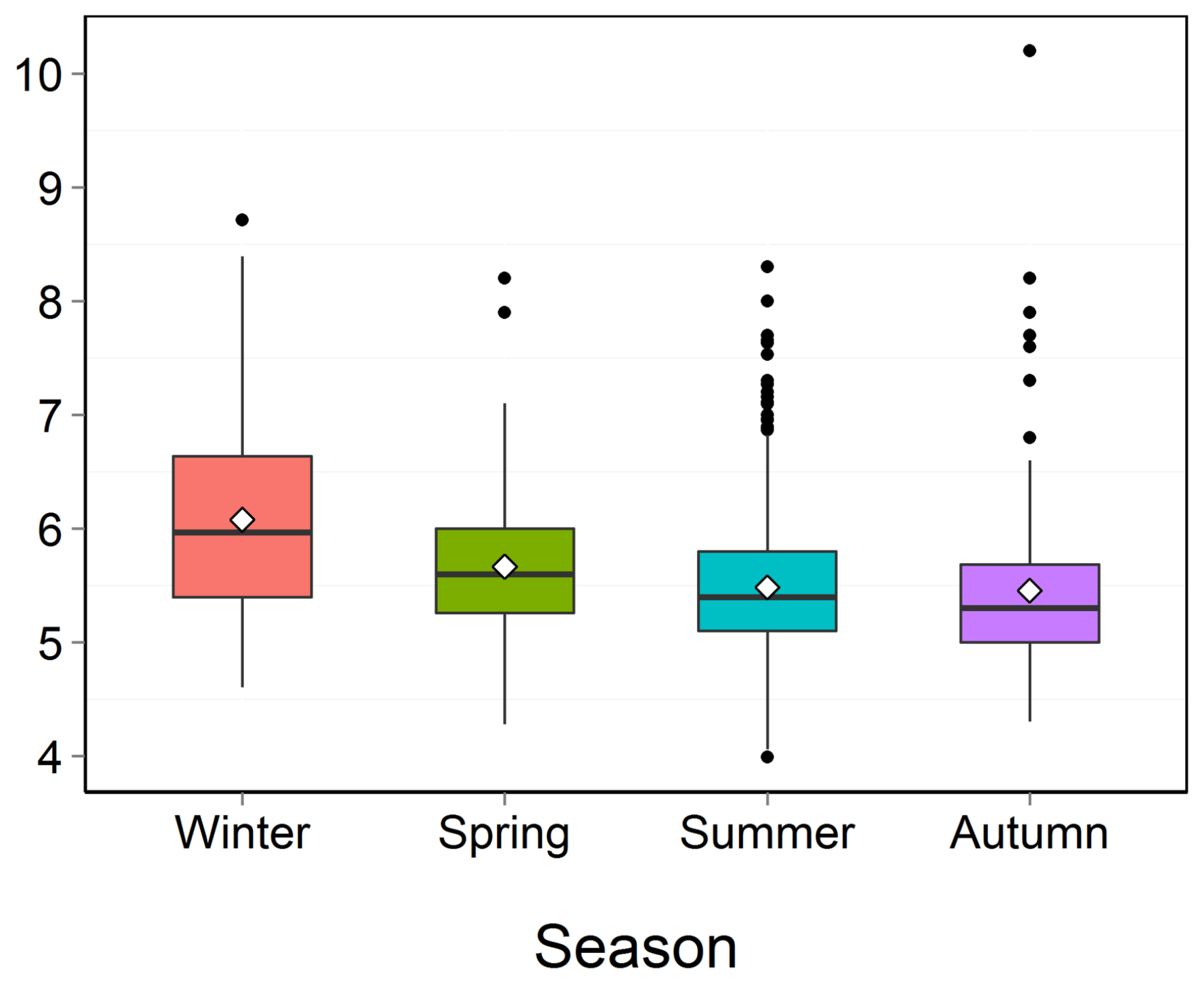

figure4.png 


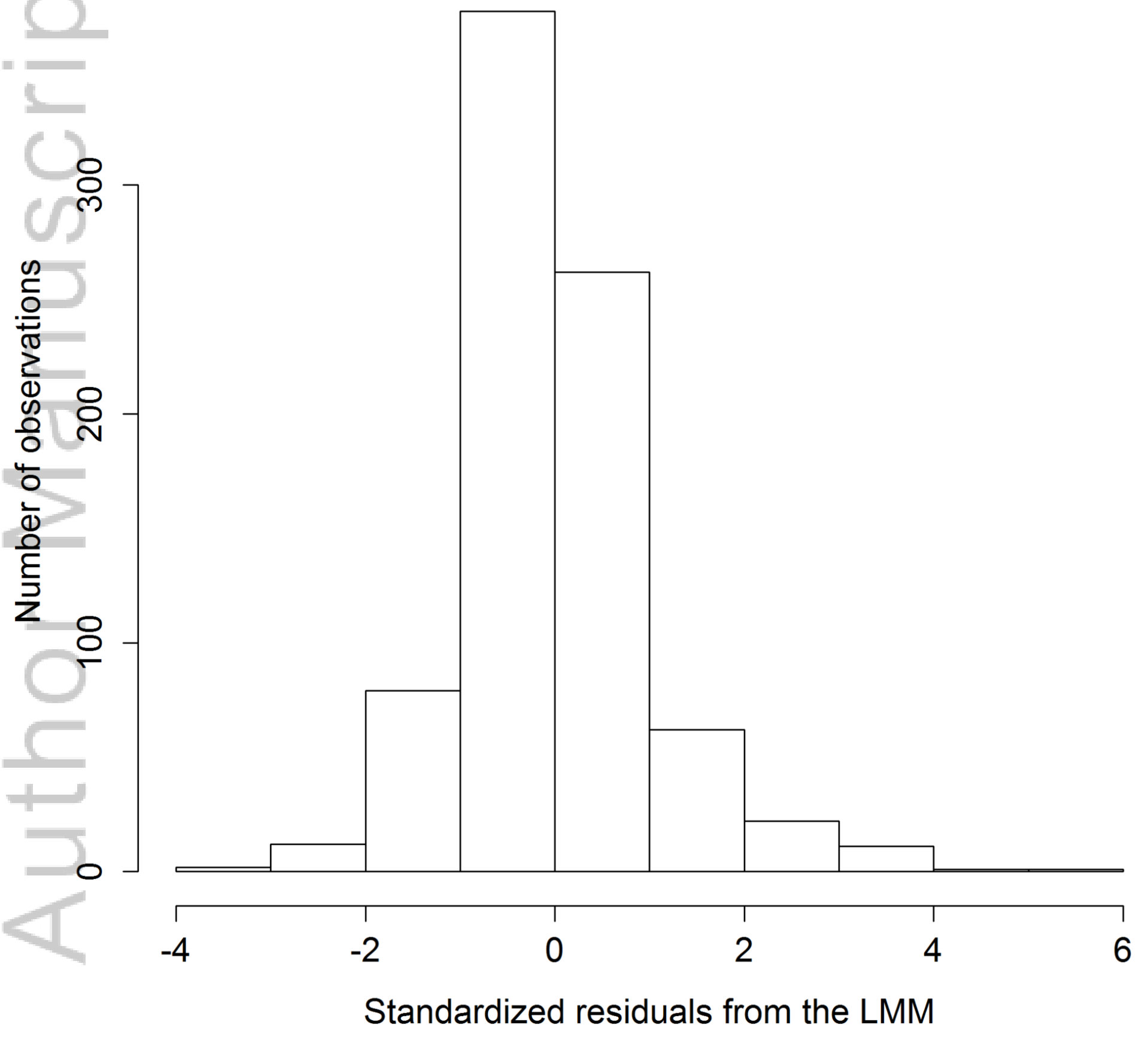

figure5.png 


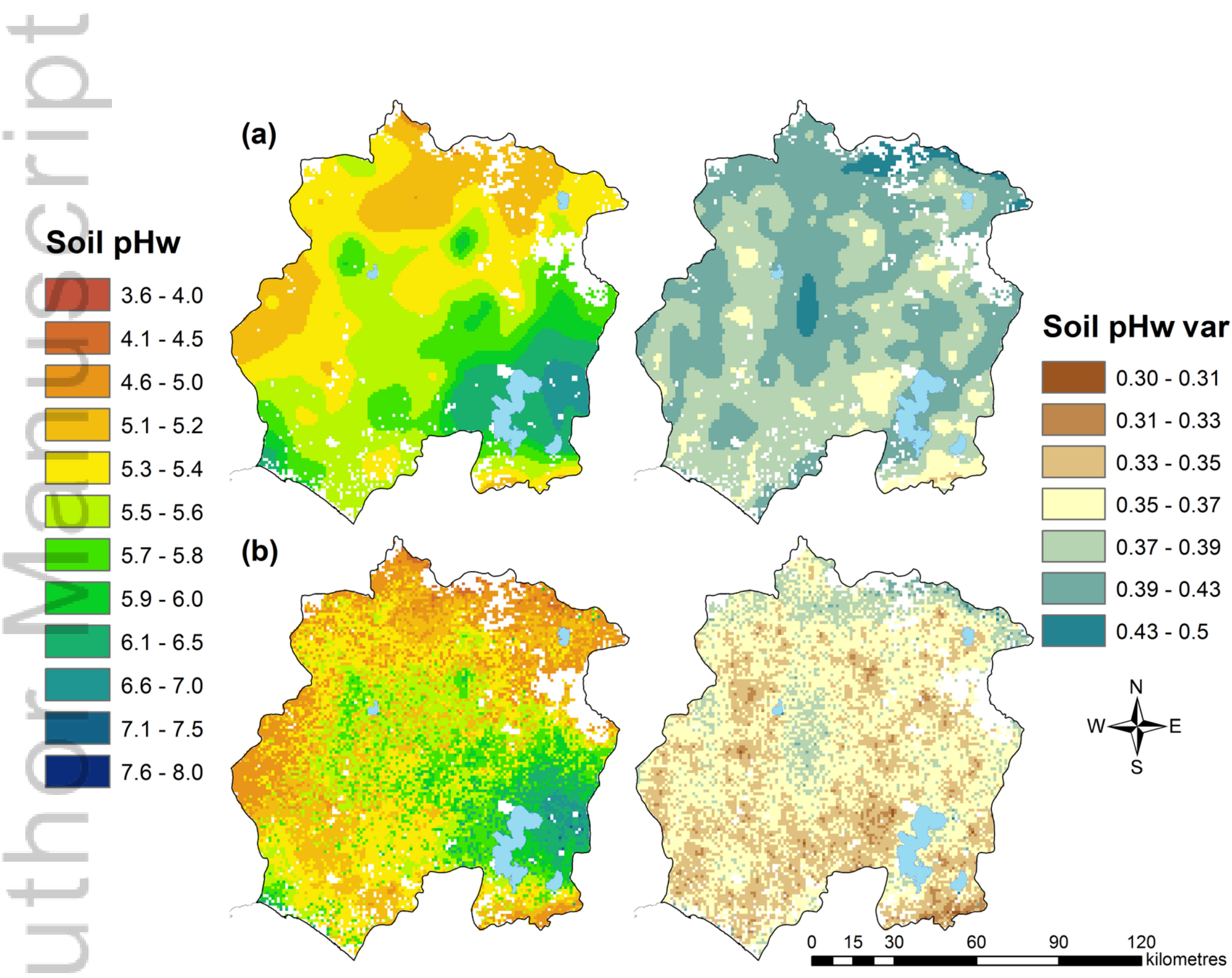

figure6.png 


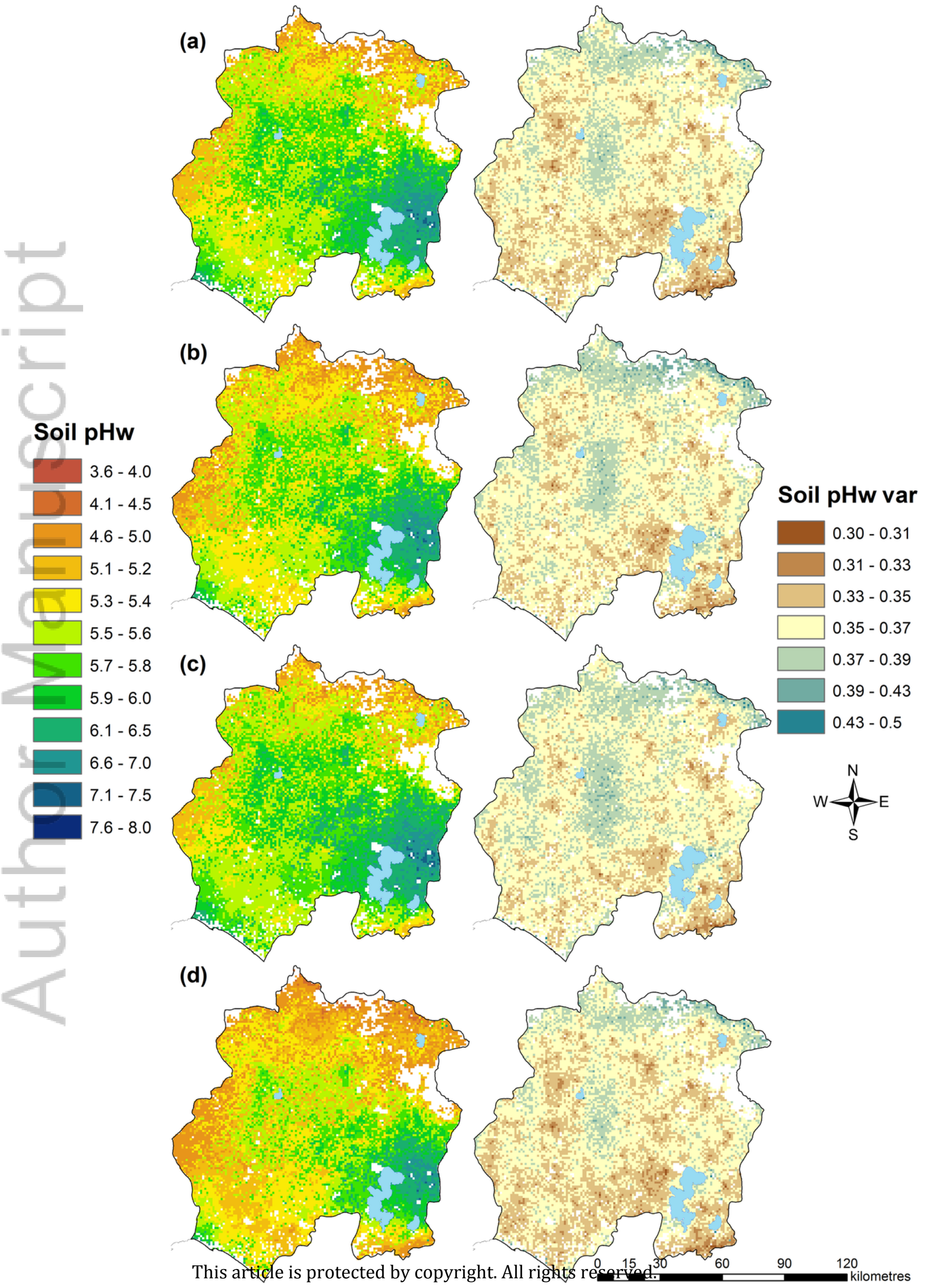




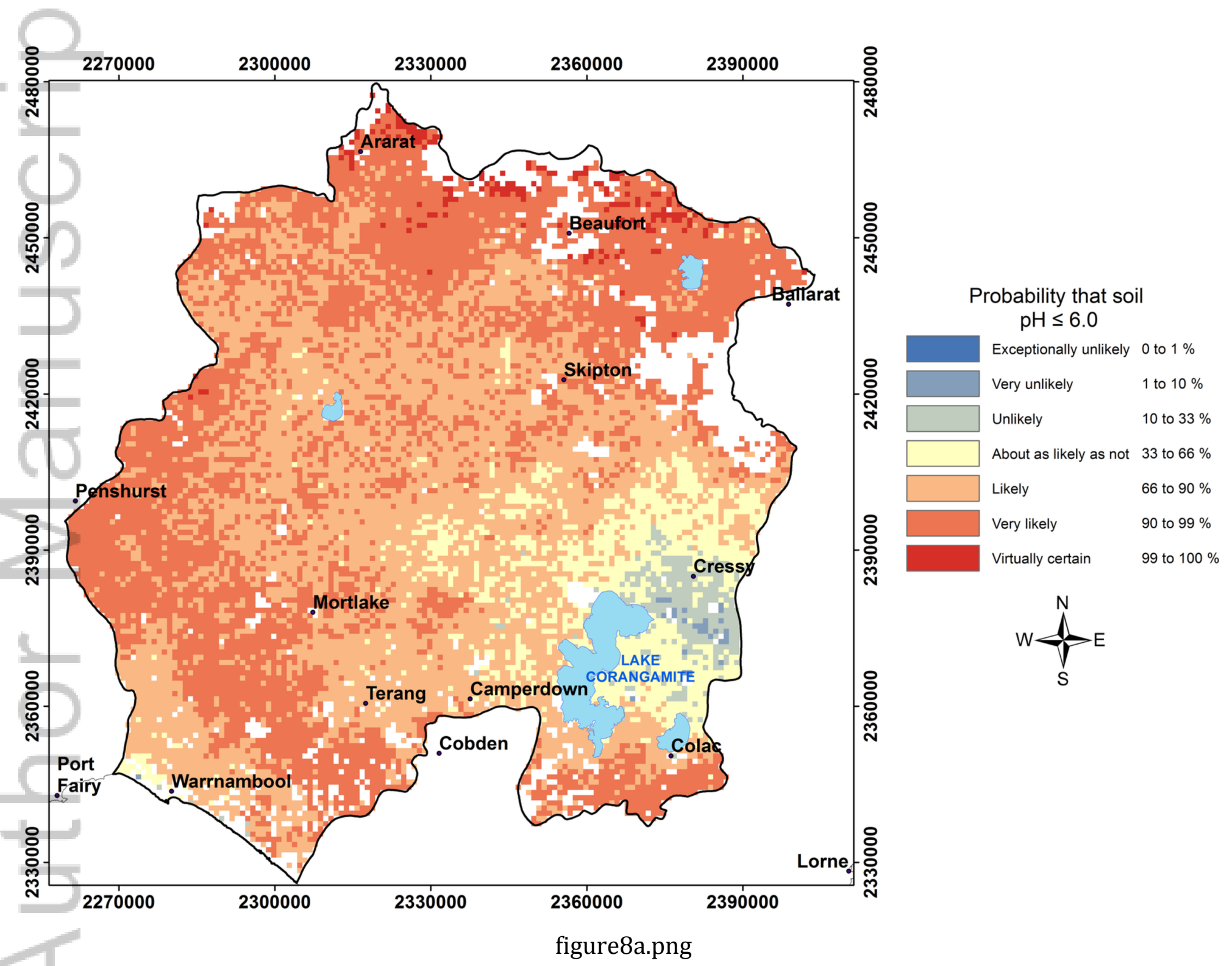

This article is protected by copyright. All rights reserved. 


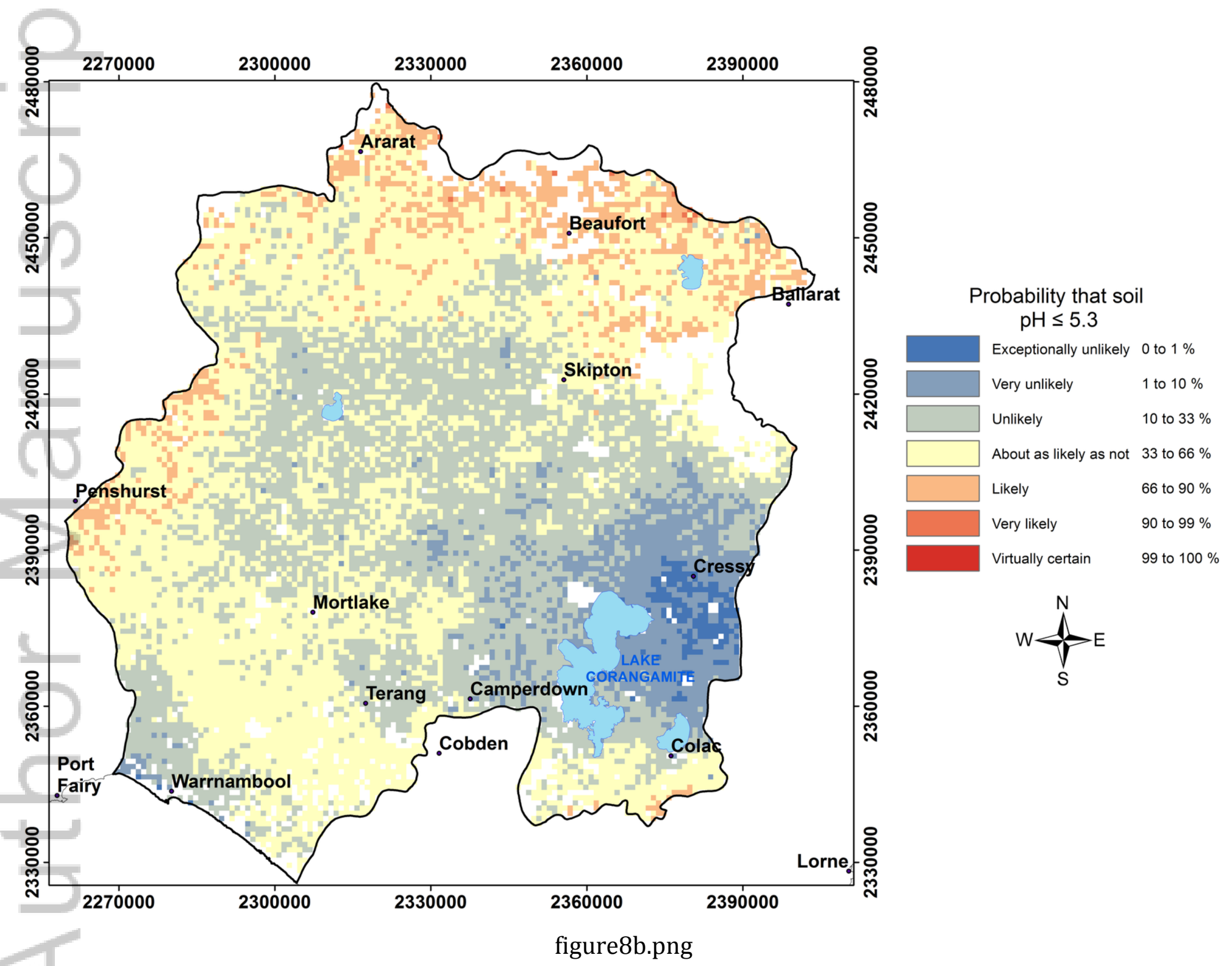

This article is protected by copyright. All rights reserved. 